\title{
Study of Aircraft Wing with Emphasis on Vibration Characteristics
}

\author{
Nataraj Kuntoji*, Dr. Vinay V. Kuppast** \\ * M.Tech Student, Department of Mechanical Engineering, Basaveshwar Engineering College, (Affl. to \\ Visvesvaraya Technological University, Belgaum) Bagalkot, India \\ Email: nataraj.kuntoji@gmail.com \\ ** Professor, Department of Mechanical Engineering, Basaveshwar Engineering College, (Affl. to Visvesvaraya \\ Technological University, Belgaum) Bagalkot, India \\ Email: vinay_kuppast@yahoo.com
}

\begin{abstract}
It is essential that the structural stability of the aircraft wings is a major consideration in the design of the aircraft. Many studies are being carried out for the design of the wings across the globe by the researches to strengthen the aircraft wings for steady and sturdy structures for dynamic conditions.

The design of the aircraft wing using NACA standards is been discussed in this work. The wing analysis is carried out by using computer numerical analysis tool, viz., CAD/CAE and CFD. The necessary inputs for carrying out the structural analysis with emphasis on the vibration are obtained by CFD analysis. The deformation of the wing structures are investigated with respect to the standard airflow velocity. The velocity of air at the inlet is taken as $122 \mathrm{~m} / \mathrm{s}(438 \mathrm{~km} / \mathrm{h})$, considering service ceiling of $7625 \mathrm{~m}$ at moderate temperature. The modal analysis is considered to analyse the wing to determine the natural frequency for vibration characteristics of the wing structure. The study of the effect of the stresses and deformations of the wing structure on the vibration characteristics of the wing is carried out to understand the effect of stress on natural frequency of the aircraft wing structure. Hence it is possible to correlate the effect of wind pressure on the vibration of the wing structure for particular design of the wing (NACA).

The CFD results revealed that the pressure on the upper surface of the wing for all the wing section planes (butt planes-BL) is less, about $-4.97 \mathrm{e} 3 \mathrm{~N} / \mathrm{mm} 2$, as compared to the pressure on the lower surface, about $1.08 \mathrm{e} 4$ $\mathrm{N} / \mathrm{mm} 2$, which satisfy the theory of lift generation. The pre-stressed modal analysis shows the correlation of the stress, deformation and the corresponding mode of vibration. It is found that the maximum deformation of $17.164 \mathrm{~mm}$ is corresponding to the modal frequency of $179.65 \mathrm{~Hz}$ which can be considered as design frequency of the wing structure. However the fundamental natural frequency of the wing structure is $10.352 \mathrm{~Hz}$ for the deformation of $11.383 \mathrm{~mm}$.

Keywords: Structural analysis, Modal analysis, CATIA V5R19, CFD
\end{abstract}

\section{INTRODUCTION}

Aircraft to fly successfully in air depends on four aerodynamic forcesthey are thrust, drag, gravity and lift. Thrust is the forward speed of the plane. Drag is a backward force exerted on the plane, a result of the friction between aircraft wing and air. Lift is the upward force acting on the plane. Weight of the aircraft itself is considered as gravity. Lift and gravity is one pair of opposing forces; thrust and drag is another pair of opposing forces. If thrust must exceed the level of drag the plane will move faster, similarly lift must exceed gravity to go up.

The predominant function of the aircraft wing is to generate sufficient lift (L). Drag (D) and nose-down pitching moment $(\mathrm{M})$ are the two other components of wing. The main primary aim of the wing design is to maximize the lift and minimize the other two components. The wing is considered as a lifting surface and works on lift generation theory, that lift is produced due to the pressure difference between lower and upper surfaces.

The particular wing design depends upon many factors for example, size, weight, use of the aircraft, desired landing speed, and desired rate of climb. In some aircraft, the larger compartments of the wings are used as fuel tanks. The wings are designated as right and left, corresponding to the right- and left-hand sides of a pilot seated in the aircraft. 


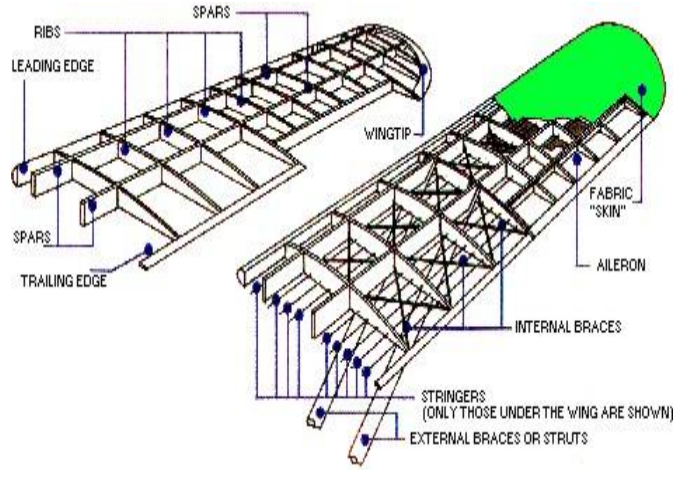

Fig 1: Wing construction

One method of wing construction is shown in Fig.1 [1]. In this illustration, two main spars are used with ribs placed at frequent intervals between the spars to develop the wing contour. This is called "two-spar" construction. Other variations of wing construction include "mono spar (open spar), multi spar (three or more spars), and box beam." In the box beam construction, the stringers and spar like sections are joined together in a box-shaped beam. Then the remainder of the wing is constructed around the box.

The skin is attached to all the structural members and carries part of the wing loads and stresses. During flight, the loads imposed on the wing structure act primarily on the skin. From the skin, the loads are transmitted to the ribs and then to the spars. The spars support all distributed loads as well concentrated weights, such as a fuselage, landing gear, and nacelle. Corrugated sheet aluminum alloy is often used as a sub covering for wing structures. The Lockheed P-3 Orion wing is an example of this type of construction. Inspection and access panels are usually provided on the lower surface of a wing. Drain holes are also placed in the lower surfaces. Walkways are provided on the areas of the wing where personnel should walk or step. The substructure is stiffened or reinforced in the vicinity of the walkways to take such loads. Walkways are usually covered with a nonskid surface. Some aircraft have no built-in walkways. In these cases removable mats or covers are used to protect the wing surface. On some aircraft, jacking points are provided on the underside of each wing. The jacking points may also be used as tie down fittings for securing the aircraft.

If the aircraft is large station numbering system is used to locate large assemblies, such as fuselage stations (FS) measured along the length of the aircraft, increasing from nose tip to tail. Generally station 0 is somewhere in front of the airplane. Water lines (WL) measured along the height of the aircraft, from ground up. Butt lines (BL) are measured either side of the aircraft and centerline is considered as mid of the airplane. A butt line represents the stations along the wing as shown in Fig.2.

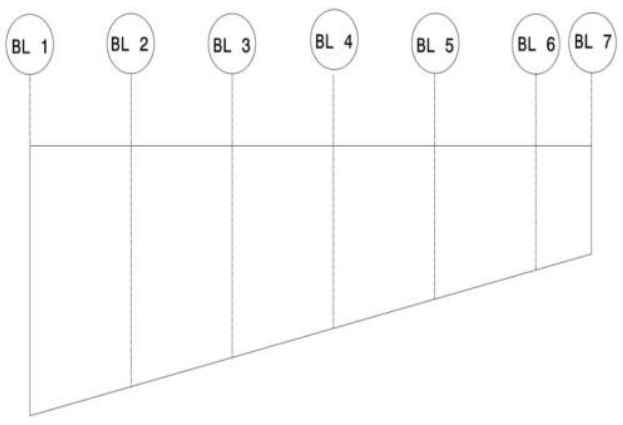

Fig.2: Wing station lines

The specifications used in the design of General Mooney M20TN Acclaim are considered as the input to the present work [2].

\section{LITERATURE REVIEW}

The purpose of the literature survey is to study the works of different researchers concerned with the detailed study of the air craft wing design. Also to find out the scope for any new methods of design by which the design process is made simple, robust, less time consuming and cost effective. The literature survey is entirely based on the previous research methods. It is desired to explore the application of the fundamental properties such as vibration which plays an important role in the failure of the structure. Hence the literature survey is carried out emphasizing the structural design of the aircraft wing subjected to vibration.

Design of aircraft wing is totally depends on airfoil design or selection, during the 1930's several families of airfoils and camber lines were developed by the NACA was a U.S. federal agency. NASA Langley Research Centre sponsored the development of computer programs for generation of ordinates of standard NACA airfoils. Existing airfoil sections can be selected easily for referring to the .N. Jacobs, K.E. Ward, \& R.M. Pinkerton. NACA Report No. 460. [3]

Several researchers expressed their view regarding difficulty in solving analytically the aerodynamic problems. Huge experimental expenses are involved in solving aerodynamic problems. Hence they preferred numerical methods. Nguyen Minh Triet et.al in their paper digitally (using $\mathrm{CAD}, \mathrm{CAE}$ and $\mathrm{CFD}$ ) calculated the lift and drag forces by varying the inlet velocity from 0 to $50 \mathrm{~m} / \mathrm{s}$ results were compared with the theoretical results. [4]

Kakumani Sureka and R Satya Meher in their paper they modelled A300 aircraft wing using standard NACA 64215 airfoil with spars and ribs 
digitally using different materials. They arrived to the conclusion that Aluminium alloy 7068 is preferred over Aluminium alloy in order to give the more strength to the structure. [5]

Sudhir Reddy Konayapalli and Y Sujatha discussed the aircraft wing design. They concluded that static pressure was increased with increase in the angle of attack. Dynamic pressure on lower surface was decreasing with increasing angle of attack whereas static pressure was increasing on lower surface [6]

Lica Flore and Albert Arnau Cubillo presented the results of the dynamical behaviour on an aircraft wing structure. The study has consisted strain gauges to test aircraft wing dynamically in which the vibration parameters of the structure have been determined. [7]

Farrukh Mazhar and Abdul Munem Khan were used implicit $\mathrm{CAD}$ model and aerodynamic CFD analysis of the vehicle as design input, and employing Artificial Neural Networks they concluded that the wing made up of composite material was lighter in weight as compared to a similar wing made from aluminium, and sufficiently strong enough to meet all in-flight load conditions and factor of safety. [8]

\section{CAD MODELLING OF AIRCRAFT WING}

The solid modelling of the aircraft wing is made using CAD tool CATIA V5 R19 to develop the solid model of the wing. The modelling of the aircraft wing structure is explained in the following steps.

I. Generation of the airfoils at the root and tip using the NACA profiles.

1. Plot the points calculated from the NACA profile standards [9]. Plot the points using the option: Points using co-ordinates

\begin{tabular}{|c|c|c|c|}
\hline \multicolumn{5}{|c|}{ As per NACA 63-215 } \\
\hline \multicolumn{4}{|c|}{$\begin{array}{c}\text { Stations and ordinates given } \\
\text { in per cent of airfoil chord) }\end{array}$} \\
\hline Upper Surface & \multicolumn{2}{c|}{ Lower Surface } \\
\hline Station & Ordinate & Station & Ordinate \\
\hline 0 & 0 & 0 & 0 \\
\hline 0.5 & 1.3786 & 0.5 & -1.0398 \\
\hline 0.75 & 1.6465 & 0.75 & -1.2927 \\
\hline 1.25 & 2.0754 & 1.25 & -1.6759 \\
\hline 2.5 & 2.8678 & 2.5 & -2.3445 \\
\hline 5 & 4.0291 & 5 & -3.276 \\
\hline 7.5 & 4.9045 & 7.5 & -3.9589 \\
\hline 10 & 5.6134 & 10 & -4.4985 \\
\hline 15 & 6.7137 & 15 & -5.3147 \\
\hline 20 & 7.5079 & 20 & -5.8818 \\
\hline 25 & 8.0583 & 25 & -6.2502 \\
\hline 30 & 8.3985 & 30 & -6.4471 \\
\hline 35 & 8.5297 & 35 & -6.4694 \\
\hline
\end{tabular}

\begin{tabular}{|c|c|c|c|}
40 & 8.4553 & 40 & -6.3169 \\
\hline 45 & 8.1924 & 45 & -6.0053 \\
\hline 50 & 7.7672 & 50 & -5.5608 \\
\hline 55 & 7.2048 & 55 & -5.0096 \\
\hline 60 & 6.529 & 60 & -4.3769 \\
\hline 65 & 5.7571 & 65 & -3.682 \\
\hline 70 & 4.9129 & 70 & -2.9514 \\
\hline 75 & 4.0219 & 75 & -2.2141 \\
\hline 80 & 3.1123 & 80 & -1.5033 \\
\hline 85 & 2.2185 & 85 & -0.8605 \\
\hline 90 & 1.3741 & 90 & -0.3318 \\
\hline 95 & 0.6202 & 95 & 0.0143 \\
\hline 100 & 0 & 100 & 0 \\
\hline \multicolumn{5}{|c|}{ L.E. radius $=1.473$ percent c } \\
\hline \multicolumn{5}{|c|}{ slope mean line at LE $=0.0842$} \\
\hline
\end{tabular}

\begin{tabular}{|c|c|c|c|}
\hline \multicolumn{4}{|c|}{ As per NACA 64-412 } \\
\hline \multicolumn{4}{|c|}{$\begin{array}{l}\text { (Stations and ordinates given } \\
\text { in per cent of airfoil chord) }\end{array}$} \\
\hline \multicolumn{2}{|c|}{ Upper Surface } & \multicolumn{2}{|c|}{ Lower Surface } \\
\hline Station & Ordinate & Station & Ordinate \\
\hline 0 & 0 & 0 & 0 \\
\hline 0.5 & 1.241 & 0.5 & -0.7391 \\
\hline 0.75 & 1.4656 & 0.75 & -0.92 \\
\hline 1.25 & 1.8291 & 1.25 & -1.1787 \\
\hline 2.5 & 2.5053 & 2.5 & -1.5879 \\
\hline 5 & 3.5203 & 5 & -2.1181 \\
\hline 7.5 & 4.3059 & 7.5 & -2.4974 \\
\hline 10 & 4.9575 & 10 & -2.794 \\
\hline 15 & 6.0007 & 15 & -3.2444 \\
\hline 20 & 6.7896 & 20 & -3.5607 \\
\hline 25 & 7.3781 & 25 & -3.7724 \\
\hline 30 & 7.7909 & 30 & -3.8892 \\
\hline 35 & 8.0426 & 35 & -3.9174 \\
\hline 40 & 8.1165 & 40 & -3.8348 \\
\hline 45 & 7.9859 & 45 & -3.6088 \\
\hline 50 & 7.6851 & 50 & -3.2724 \\
\hline 55 & 7.248 & 55 & -2.8612 \\
\hline 60 & 6.6952 & 60 & -2.3979 \\
\hline 65 & 6.0431 & 65 & -1.9025 \\
\hline 70 & 5.3061 & 70 & -1.394 \\
\hline 75 & 4.4979 & 75 & -0.8929 \\
\hline 80 & 3.6355 & 80 & -0.4262 \\
\hline 85 & 2.7387 & 85 & -0.0286 \\
\hline 90 & 1.829 & 90 & 0.2528 \\
\hline 95 & 0.9238 & 95 & 0.3444 \\
\hline 100 & 0 & 100 & 0 \\
\hline \multicolumn{4}{|c|}{ L.E. radius $=1.004$ percent $\mathrm{c}$} \\
\hline & 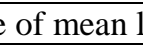 & LE & J \\
\hline
\end{tabular}

2. Create the splines making the top and bottom part of the aerofoil. Leave the leading edge point to give the leading edge radius. 


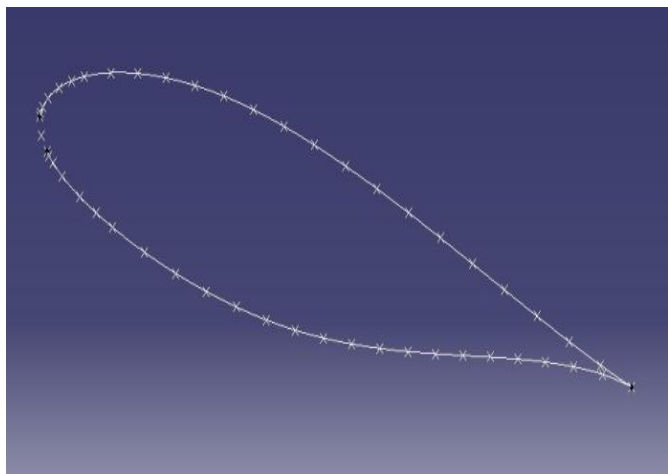

Fig.3: Upper and Lower surface splines of NACA 63215

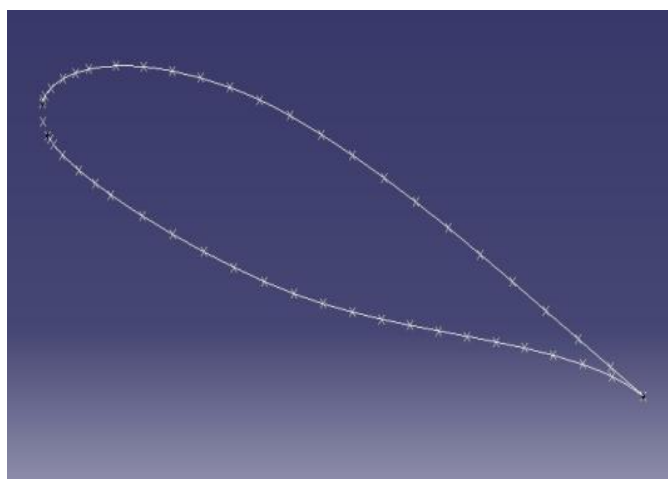

Fig.4: Upper and Lower surface splines of NACA 64412

3. Generation of wing surface using the aerofoil profiles at the root and the tip.

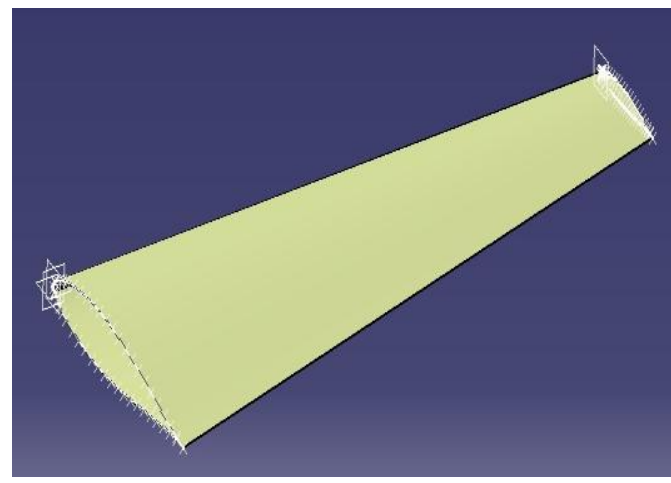

Fig.5: Master Geometry (Wing Surface) of Mooney M20TN Acclaim Aircraft Wing

The master geometry of Mooney M20TN Acclaim Aircraft Wing is shown in Fig.5. This is the CAD model which is considered for carrying out CFD analysis to find out the pressure distribution. This data is vital in carrying out structural analysis and then prestressed modal analysis for the study of vibration characteristics of the wing.

\section{RESULTS AND DISCUSSIONS}

Aerodynamic complications in general are often difficult to solve by analytical methods. Experimental or numerical simulation can be used to analyze these computational prototypes. To solve aerodynamic problems experimentally heavy cost are involved; hence the numerical method is more preferred. This work furnishes the modeling and simulating procedure of computational fluid dynamic (CFD) problem on an aircraft wing model, using root airfoil section as NACA 63-215 and tip airfoil section as NACA 64-412. Pressure and velocity distribution on the surface of an aircraft wing is analyzed using ANSYS Fluent.

The fluid flow is considered as airflow. The flow properties are chosen to be similar to that used in the experiment, such as the density is $1.225 \mathrm{~kg} / \mathrm{m} 3$, and the kinematics viscosity is $1.7894 \mathrm{e}-5$. All parameters of the above materials are applied to set for simulations.

In order to achieve more accurate results, a bottom up approach method has been adopted in the design. In bottom up approach the wing is first modeled without internal structural member (i.e. spars, ribs etc.) and then analyzed to arrive aerodynamic pressure loads.

ANSYS Fluent is able to provide several graphic and animation types, such as pressure and velocity distributions etc.

Fig.6 and fig.7 shows pressure distribution contours in the airflow, when the velocity applied at the inlet is $122 \mathrm{~m} / \mathrm{s}(438 \mathrm{~km} / \mathrm{h})$. As can be noticed, the highpressure regions appear at the leading edge and on the lower surface of airfoil. The low pressure region appears on the upper surface of the airfoil. This analysis is accurate with the theory of lift generation.

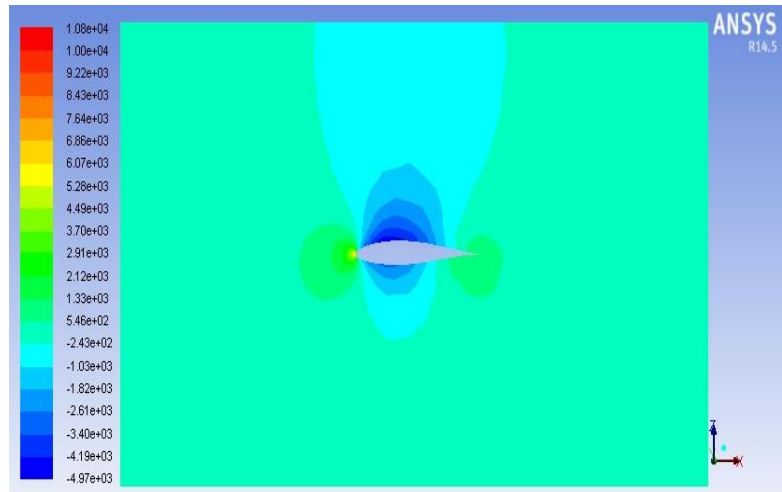

Fig.6: Pressure Distribution at the wing root

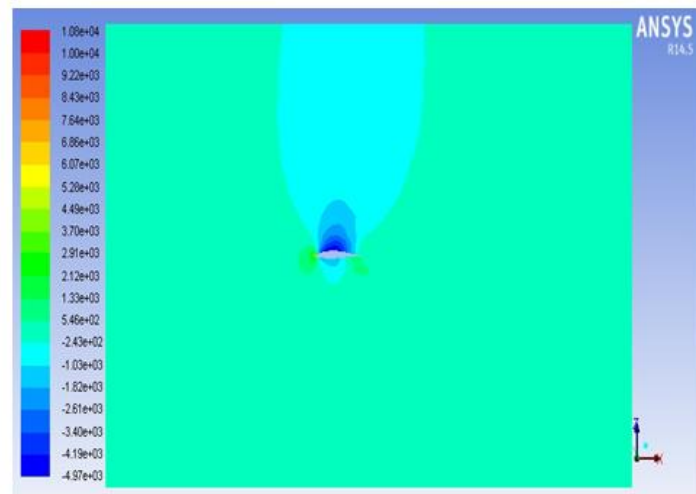

Fig.7: Pressure Distribution at the wing tip. 
Velocity is also an important property to be studied in the airflow over the airfoil section. Pressure is inversely proportional to velocity.

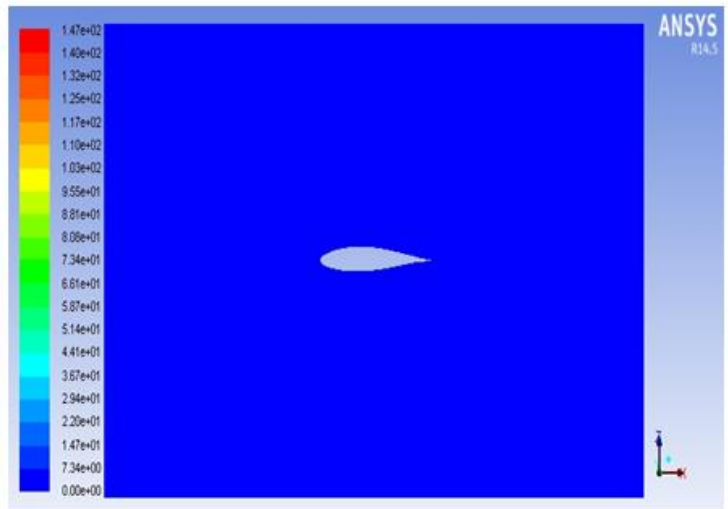

Fig.8: Velocity Distribution at the wing root.

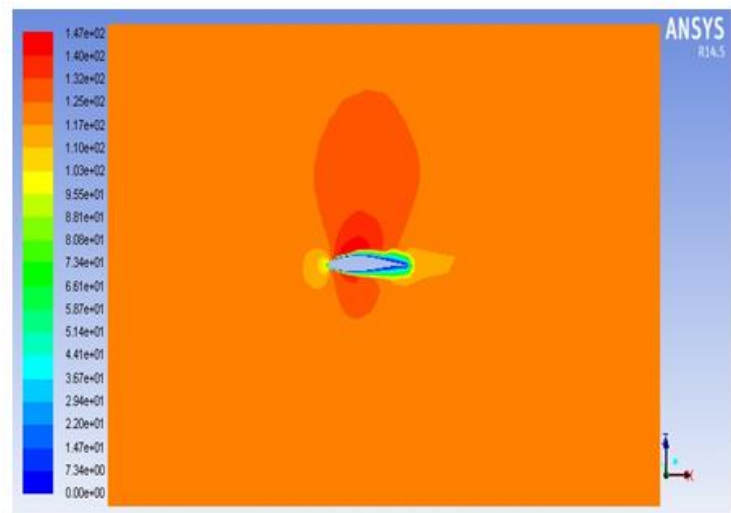

Fig.9: Velocity Distribution at the mid span of the wing.

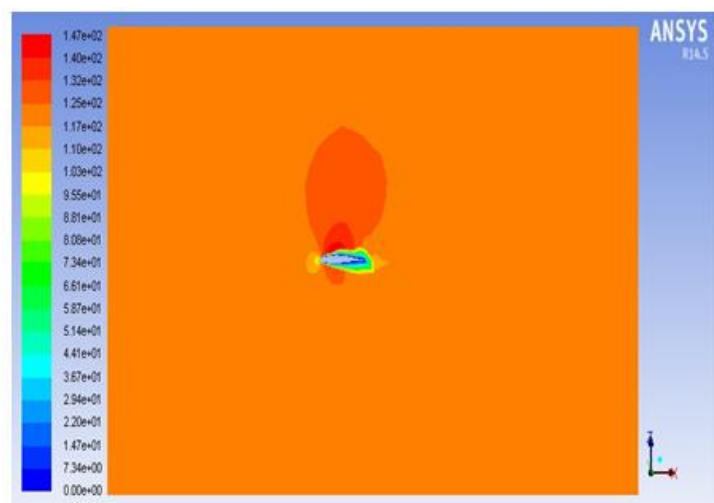

Fig.10: Velocity Distribution at the wing tip

Fig.8 to Fig.10 shows velocity distribution contours in the airflow, when the velocity applied at the inlet is $122 \mathrm{~m} / \mathrm{s}(438 \mathrm{~km} / \mathrm{h})$. As can be noticed, the highvelocity regions appear on the upper surface of airfoil. The low velocity region appears on the lower surface of the airfoil. This analysis is accurate with the theory of lift generation.

\section{STRUCTURAL ANALYSIS OF AIRCRAFT WING}

In this project detailed design of aircraft wing using NACA standards is made by using CATIA V5 $\mathrm{R} 19$. Stress analysis of the wing is carried out to compute the stresses, deformation and strains at aircraft wing structure. Finite Element Approach is applied for finding stresses using ANSYS workbench 14.5. Pressure loads are applied on the wing to carry out structural analysis.

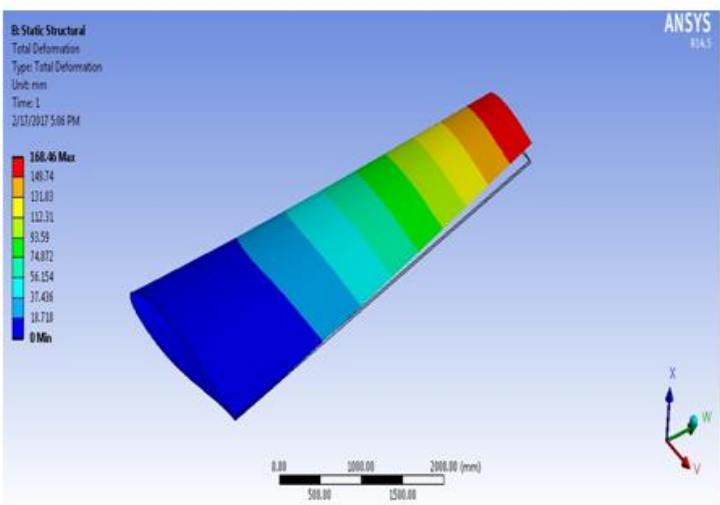

Fig.11: Total deformation in wing

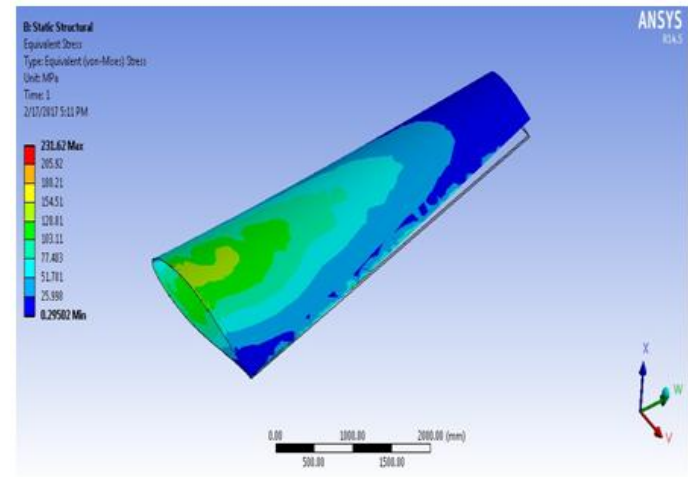

Fig.12: Equivalent (von-Mises) stress in wing

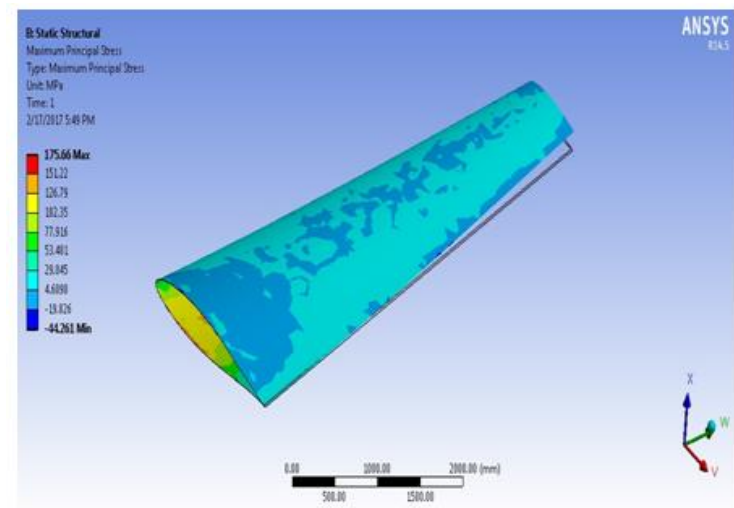

Fig.13: Maximum principal stress in wing 


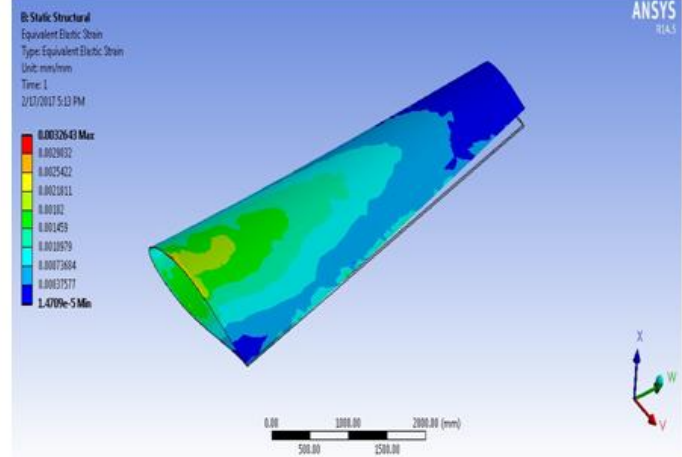

Fig.14: Equivalent strain in wing

Fig.12 shows the Equivalent tensile stress or von-Mises stress. It states that the material starts to yield when the von-Mises stress reaches a critical value, yield strength. Uniform stress distribution is observed all over the wing but maximum stress is developed close to the root section of wing. In this case, the von-Mises stress observed in the wing analysis is $231.62 \mathrm{Mpa}$ which is lower than the yield strength of the aluminium alloy. Fig. 13 shows maximum principal stress distribution of the wing under pressure load. The maximum principal stress noticed in the structure is $175.66 \mathrm{Mpa}$ which is lower than the yield strength of the material. The structure is safe because the stress magnitude which is obtained from the analysis is less than the yield strength of the structural material. Deflection of the wing is shown in Fig.11, the wing bends upwards because of pressure load.

\section{PRE-STRESSED MODAL ANALYSIS}

Dynamic properties of aircraft wing structure can be studied by modal analysis under vibration excitation. In aircraft wing vibration occurs due to the lift load and the load due to mounting engine on the wing. The modal analysis uses the overall mass and stiffness property of the structure to find the various periods at which it will naturally resonate. Dynamic analysis comprised of deformation calculations due to inertial loads at higher load factors and estimation of natural frequencies and mode shapes. The mode shapes, deformation and corresponding frequencies are shown in figures from 15 to 24 and table 1 .

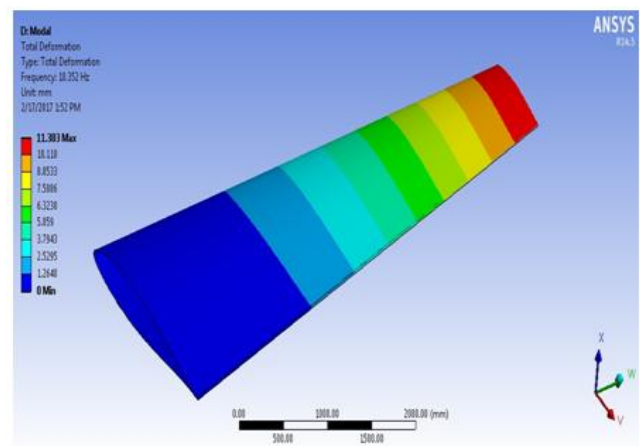

Fig.15: Wing deformation at mode 1

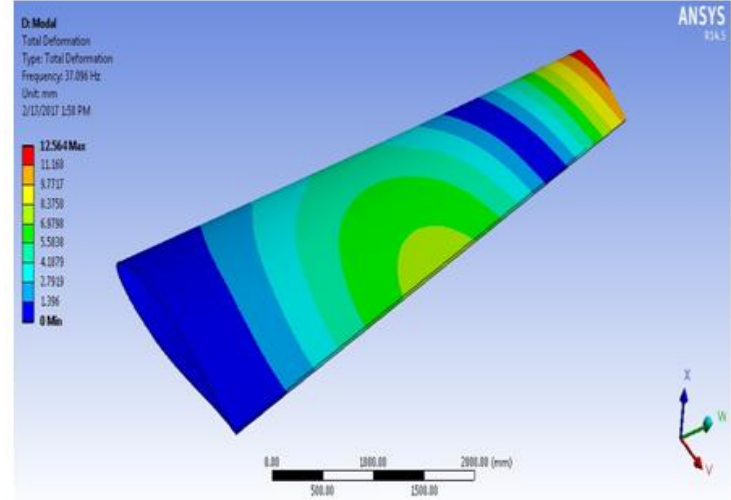

Fig.16: Wing deformation at mode 2

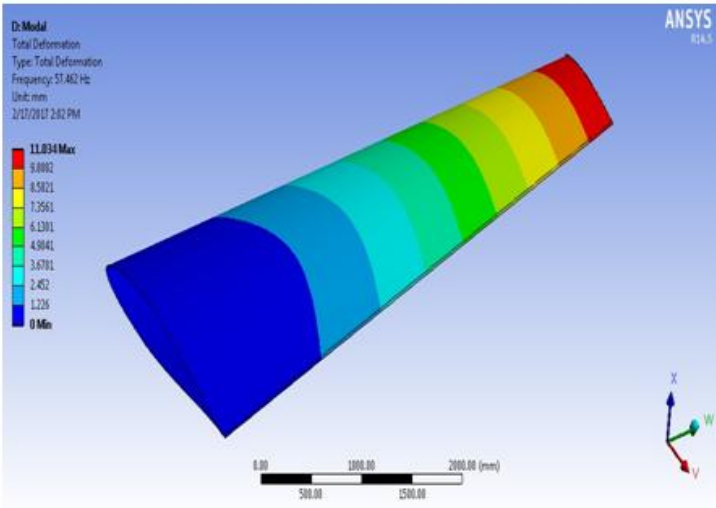

Fig.17: Wing deformation at mode 3

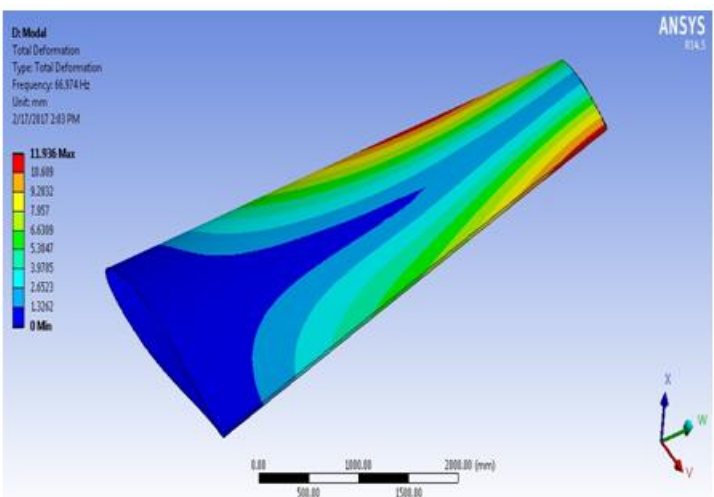

Fig.18: Wing deformation at mode 4

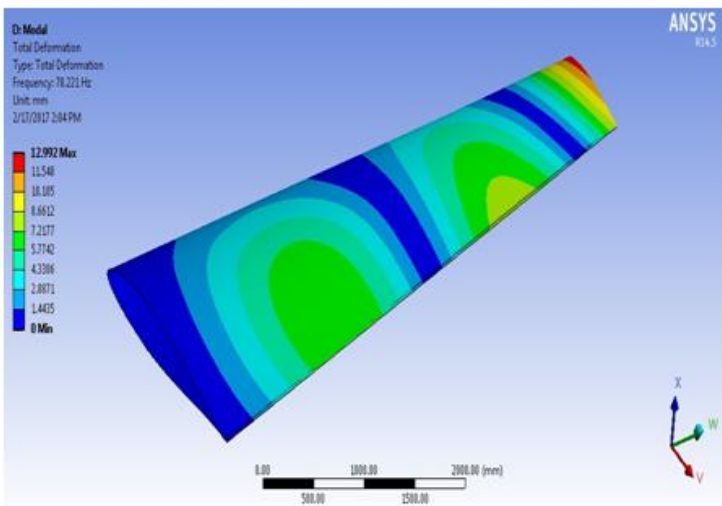

Fig.19: Wing deformation at mode 5 


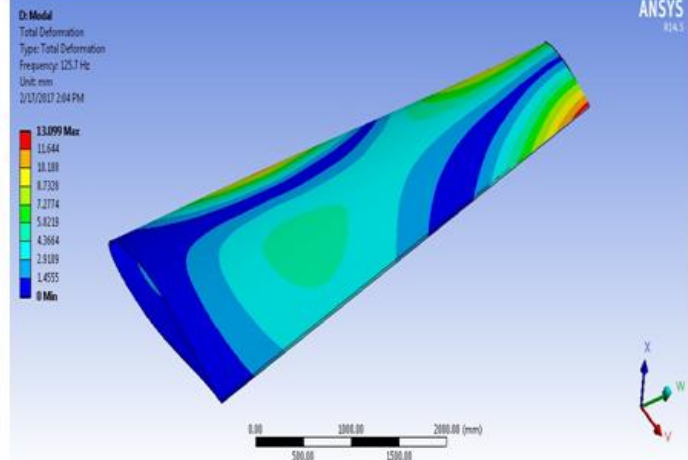

Fig.20: Wing deformation at mode 6

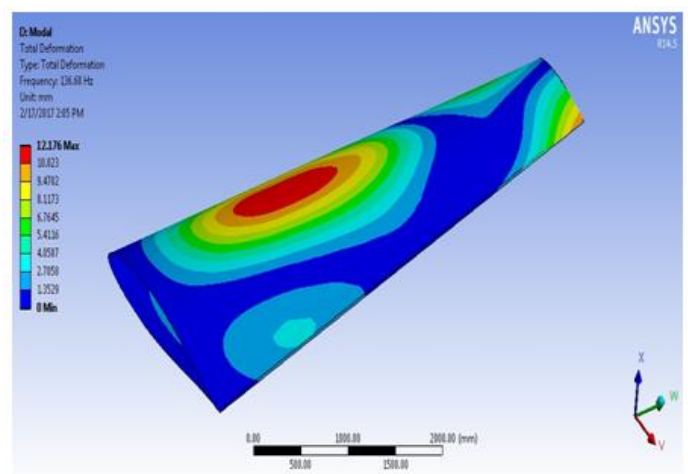

Fig.21: Wing deformation at mode 7

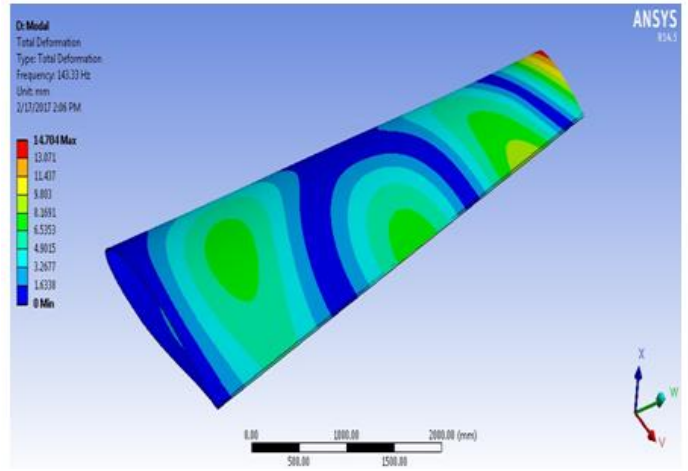

Fig.22: Wing deformation at mode 8

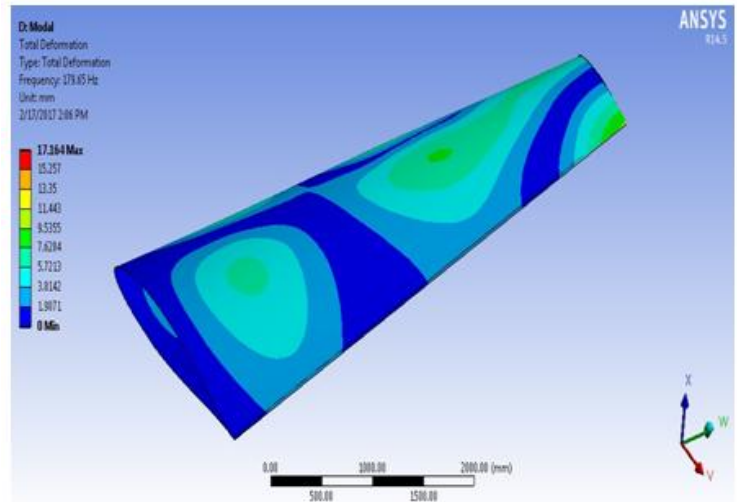

Fig. 23: Wing deformation at mode 9

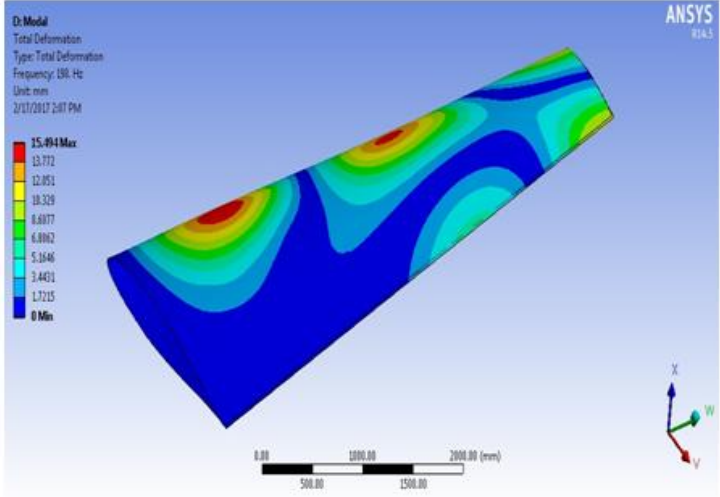

Fig. 24: Wing deformation at mode 10

Table 1: Natural Frequency, Max Deformation and Mode shapes

\begin{tabular}{|c|c|c|}
\hline Mode No. & Frequency $(\mathrm{Hz})$ & $\begin{array}{c}\text { Max. Deformation } \\
(\mathrm{mm})\end{array}$ \\
\hline 1 & 10.352 & 11.383 \\
\hline 2 & 37.096 & 12.564 \\
\hline 3 & 57.462 & 11.034 \\
\hline 4 & 66.974 & 11.936 \\
\hline 5 & 78.221 & 12.992 \\
\hline 6 & 125.7 & 13.099 \\
\hline 7 & 136.68 & 12.176 \\
\hline 8 & 143.33 & 14.704 \\
\hline 9 & 179.65 & 17.164 \\
\hline 10 & 198 & 15.494 \\
\hline
\end{tabular}

\section{CONCLUSIONS AND SCOPE FOR FUTURE WORK}

The use of computer aided engineering procedures to model, analyze and optimize proves to be the most economic, reliable, and faster and user friendly method to be adopted by the researchers and the engineers to cope up the industry requirements for design changes. The Computer Aided Design Tools and NACA standards have been accomplished to design the wing structure. The vibration characteristics of the wing structures are studied by modal analysis to find the natural frequency of the wing structures.

The CFD results revealed that the pressure on the upper surface of the wing for all the wing section planes (butt planes-BL) is less, about $-4.97 \mathrm{e} 3 \mathrm{~N} / \mathrm{mm} 2$, as compared to the pressure on the lower surface, about $1.08 \mathrm{e} 4 \mathrm{~N} / \mathrm{mm} 2$, which satisfy the theory of lift generation. The pre-stressed modal analysis shows the correlation of the stress, deformation and the corresponding mode of vibration. It is found that the maximum deformation of $17.164 \mathrm{~mm}$ is corresponding to the modal frequency of $179.65 \mathrm{~Hz}$ which can be considered as design frequency of the wing structure. However the fundamental natural frequency of the wing structure is $10.352 \mathrm{~Hz}$ for the deformation of $11.383 \mathrm{~mm}$.

The future scope of the research would be the simulation of the wing in the design phase itself by using this method. The Noise, Vibration and Harshness (NVH) studies can give an insight for the design of the aircraft wing for sturdy and stable structure. The aircraft wing 
design can be modified or optimized by using this method would lead to a new method to incorporate the $\mathrm{NVH}$ problems in aircraft design using CAE approach.

\section{REFERENCES}

[1]. http://www.allstar.fiu.edu/aero/flight12.htm

[2]. https://en.wikipedia.org/wiki/Mooney_M20

[3]. E.N. Jacobs, K.E. Ward, \& R.M. Pinkerton. NACA Report No. 460, "The characteristics of 78 related airfoil sections from tests in the variable-density wind tunnel". NACA, 1933.

[4]. Nguyen Minh Triet, Nguyen Ngoc Viet, and Pham Manh Thang "Aerodynamic Analysis of Aircraft Wing" VNU Journal of Science: Mathematics - Physics, Vol. 31, No. 2 (2015) 68-75.

[5]. Kakumani Sureka and R Satya Meher "Modeling and Structural Analysis on A300 Flight Wing by using ANSYS" International Journal of Mechanical Engineering and Robotics Research Vol. 4, No. 2, April 2015.

[6]. Sudhir Reddy Konayapalli and Y Sujatha "Design and Analysis of Aircraft Wing" International Journal and Magazine of Engineering, Technology, Management and Research. Volume No: 2 (2015), Issue No: 9 (September).

[7]. Lica Flore and Albert Arnau Cubillo “ Dynamic Mechanical Analysis of an Aircraft Wing with emphasis on vibration modes change with loading" International Conference of Scientific Paper AFASES 2015 Brasov, 2830 May 2015.

[8]. Farrukh Mazhar and Abdul Munem Khan “ Structural Design of a UAV Wing using Finite Element Method" 51st AIAA/ASME/ASCE/AHS/ASC Structures, Structural Dynamics, and Materials Conference $\langle$ BR $>18$ th 12 - 15 April 2010, Orlando, Florida.

[9]. http://www.pdas.com/sections6.html 